\title{
Эффекты дополнительных размещений акций
}

\author{
Токтоналиев А.P. ${ }^{11}$, Чиркова E.B. ${ }^{12}$
}

В данной статье анализируются результаты исследований дополнительных размещений акиий (seasoned equity offering, SEO). В ней освещаются иироко известные феномень SEO, наблюдаемые в различных странах, такие как эффрект объявления отрицательная реакция иень акиий на объявления о SEO, недооченка акций при SEO, долгосрочная доходность SEO.

В статье приводятся данные относительно размера отрицательной реакции на объявление о SEO, изложены гипотезы, объясняюшие данный эффект: отрицательного наклона кривой спроса на акиии, структуры капитала, высоких трансакционных издержек размещения акиий, информационная. Перечислены факторы, влияющие на величину избыточной доходности в день объявления: целевое использование средств, характер корпоративных новостей, объемы размещуения и стадии экономических циклов. В статье проанализированы результаты исследований величины недооценки и их временной динамики и зависимости размера недооченки от различных факторов, таких как биржа листинга, репутащия андеррайтера, а также описаны гипотезы, объясняющие феномен недооченки SEO: изменения профиля эмитента, «приятного послевкусия», коротких продаж, растущей власти инвестиционных банков. Авторами также рассмотрены исследования феномена пониженной доходности акций SEO в разных странах, изложены гипотезы причин ее существования: использования окон возможностей и проявление некорректно специифицированной модели.

\section{JEL: G19, G13}

Ключевые слова: дополнительные размещения акций, эффект объявления, недооченка, пониженная долгосрочная доходность

\section{Введение}

Дополнительные размещения акций являются для публичных компаний важным источником финансирования. Редко компании, чтобы привлечь акционерный капитал, выходят на фондовые рынки только один раз за свою историю - для проведения первичного размещения акций (initial public offering, IPO); многие эмитенты, осуществив IPO, возвращаются на рынок с целью дополнительного размещения. Возможность проведения SEO особенно актуальна в условиях финансового кризиса, когда корпорации, не имеющие возможности выйти на долговые рынки из-за высокого финансового рычага, вынуждены прибегать к дополнительной эмиссии. Мотивами проведения SEO являются: привлечение финансирования для реализации различных инвестиционных проектов, включая приобретение других компаний; изменение структуры капитала компании в сторону сокращения доли долга, в том числе погашение долгов; выход из бизнеса его крупных акционеров - основателей компании или инвесторов в нее на ранних стадиях.

Проблематике дополнительных размещений акций на развитых рынках посвящено множество работ, но интерес к SEO на развивающихся рынках исследователи стали проявлять относительно недавно. Наибольший интерес вызывает феномен отрицательного влияния объявления о дополнительном размещении акций на курс акций компании, наличие которого может означать, что выпуск акций передает отрицательную информацию рынку о

\footnotetext{
${ }_{11}$ Аспирант кафедры экономики и финансов фирмы экономического факультета НИУ ВШЭ.

${ }^{12}$ Канд. эконом. наук, доцент кафедры экономики и финансов фирмы экономического факультета НИУ ВШЭ.
} 
компании-эмитенте. Также предметом научного интереса являются недооценка SEO (скидка с рыночной цены уже обращающихся акций при установлении цены размещения новой эмиссии), отрицательная избыточная долгосрочная доходность акций компаний, проводящих дополнительные размещения.

\section{Реакция рынка на объявление о дополнительной эмиссии акций}

Эффект объявления о SEO определяется как избыточная доходность акций, которая обычно измеряется либо за «двухдневное окно» $[-1,0]$ - двухдневный период, заканчивающийся днем публичного объявления (день 0 ), либо за «трехдневное окно» [-1, $+1]$. Одними из первых отрицательную реакцию цены акций на объявление о дополнительной эмиссии (эффект объявления о дополнительном размещении акций) заметили Пол Аскуис и Давид Маллинз (Asquith, Mullins, 1986). Авторы выявили, что для США в период 1963-1981 годов средняя двухдневная избыточная доходность вокруг момента объявления для всей выборки составляет $-3,0 \%$, на первый взгляд она небольшая, но в силу небольших объемов дополнительных размещений по отношению к общей капитализации снижение капитализации компании в день объявления о SEO составляет $31 \%$ от привлеченных в ходе размещения средств.

Приведенная в таблице 1 сводная информация по основным исследованиям эффекта объявления о SEO вплоть до 2006 года показывает, что в США такие объявления вызывали отрицательную реакцию во все исследовавшиеся периоды: на различных выборках от 392 до 2000 размещений за разные годы избыточная доходность акций в двухдневном окне вокруг даты объявления колеблется от $-2,00$ до $-3,65 \%$. Однако на рынках Японии и Гонконга ценовая реакция на объявлении о SEO положительна ${ }^{13}$, на европейских рынках эффект объявления неоднозначный - здесь он или отрицательный, но не столь ощутимый, как в США, или вовсе положительный. Результаты варьируются в зависимости от метода и характера размещения.

Таблица 1

Результаты основных эмпирических исследований эффекта объявления о SEO

\begin{tabular}{lcccc}
\hline \multicolumn{1}{c}{ Исследование } & $\begin{array}{c}\text { Размер } \\
\text { выборки }\end{array}$ & $\begin{array}{c}\text { Период, } \\
\text { гг. }\end{array}$ & $\begin{array}{c}\text { Рынокточная } \\
\text { доходность } \\
{[-\mathbf{1 ; 0 ] , ~ \% ~}}\end{array}$ \\
\hline Asquith, Mullins (1986) & 392 & $1963-1981$ & США & $-3,00$ \\
Masulis, Korwar (1986) & 972 & $1963-1980$ & США & $-3,25$ \\
Mikkelson, Partch (1986) & 80 & $1972-1982$ & США & $-3,56$ \\
Hansen, Crutchley (1990) & 109 & $1975-1982$ & США & $-3,65$ \\
Korajczyk, Lucas, McDonald (1991) & 1247 & $1978-1983$ & США & $-2,26$ \\
Eckbo, Masulis (1992) & 1057 & $1963-1981$ & США & $-2,00$ \\
Choe, Masulis, Nanda (1993) & 1456 & $1963-1983$ & США & $-3,15$ \\
Bayless, Chaplinsky (1996) & 1881 & $1968-1990$ & США & $-2,30$ \\
Altinkilic, Hansen (2003) & 1703 & $1990-1997$ & США & $-2,23$ \\
Walker, Yost (2008) & 438 & $1997-2000$ & США & $-2,76$ \\
D'Mello, Schlingemann, & 3093 & $1982-2006$ & США & $-1,39$ \\
Subramaniam (2009) & 185 & $1985-1991$ & Япония & 0,51 \\
Kang, Stulz (1996) & 28 & $1985-1991$ & Япония & $2,21 *$ \\
Kang, Stulz (1996) & & &
\end{tabular}

\footnotetext{
${ }^{13}$ Единственное исследование реакции на японских рынках выполнено на временном интервале 1985-1991 годов, из них 1985-1989 годы являются пиком экономического пузыря, так называемого японского экономического чуда, который сопровождался пузырем на рынке акций, одним из самых масштабных за всю историю мирового фондового рынка. Таким образом, данное исследование задокументировало эффект положительной реакции не как специфику странового рынка, а как специфику момента.
} 


\begin{tabular}{lcccc} 
Slovin, Sushka, Lai (2000) & 220 & $1986-1994$ & $\begin{array}{c}\text { Велико- } \\
\text { британия }\end{array}$ & $-3,09^{*}$ \\
Gajewski, Ginglinger (2002) & 22 & $1986-1996$ & Франция & $-0,42$ \\
Gajewski, Ginglinger (2002) & 140 & $1986-1996$ & Франция & $-0,74^{* *}$ \\
Eckbo, Norli (2004) & 143 & $1980-1996$ & Норвегия & $-0,58^{* *}$ \\
Eckbo, Norli (2004) & 76 & $1980-1996$ & Норвегия & $0,95^{*}$ \\
Cronqvist, Nilsson (2005) & 160 & $1986-1999$ & Швеция & $0,37^{*}$ \\
Wu, Wang, Үaо (2005) & 306 & $1989-1997$ & Гонконг & 1,93 \\
\hline * Размещения прав. & & & \\
$\quad$ Размещение обязательство купить нераспроданные ценные бумаги.
\end{tabular}

Существуют четыре основные гипотезы, объясняющие отрицательную реакцию цены акций: 1) отрицательного наклона кривой спроса; 2) структуры капитала; 3) высоких трансакционных издержек размещения акций; 4) информационная.

\section{Гипотеза отрицательного наклона кривой спроса}

Гипотеза отрицательного наклона кривой спроса, или, как ее еще называют, гипотеза ценового давления, предложена Майроном Скоулсом (Scholes, 1972). Согласно этой гипотезе, увеличение предложения акций компанией эмитентом ведет к снижению их цены, поскольку кривая спроса на акции наклонена вниз, что в свою очередь объясняется тем, что акции каждой компании уникальны, т.е. не имеют близких заменителей. Соответственно, снижение цены в абсолютном выражении положительно коррелирует с размером эмиссии.

\section{Гипотеза структуры капитала}

При условии существования налоговых выгод заемного финансирования выпуск новых акций может снизить цену акций, если уменьшается коэффициент долговой нагрузки компании, из-за уменьшенных налоговых выгод от долгового финансирования (налогового щита). Кроме того, выбор структуры капитала может отражать ожидания менеджмента относительно перспектив компании. В этом случае высокий коэффициент долговой нагрузки сигнализирует об оптимизме менеджмента в отношении ее будущего. И напротив, выпуск новых акций является отрицательным сигналом и может снизить цену акций (Barclay, Litzenberger, 1988).

Гипотеза больших трансакиионных издержек размещения акций

Согласно данной гипотезе, снижение цены акций вслед за объявлением о дополнительном размещении отражает скидку, предоставляемую инвесторам для компенсации трансакционных издержек, которые они понесут при покупке акции нового выпуска (в основном комиссия брокеров). После того как андеррайтинговый синдикат продаст новые акции, цена акций восстановится до первоначальной величины (Barclay, Litzenberger, 1988).

\section{Информационная гипотеза}

Стюарт Майерс и Николас Мажлуф разработали модель неблагоприятного отбора, которая относится к классу моделей асимметричной информации. Согласно модели Майерса - Мажлуфа (Myers, Majluf, 1984), менеджеры владеют информацией, которой не обладают инвесторы, при этом обе стороны осознают это. Рациональный инвестор предполагает, что менеджеры принимают решение о дополнительном размещении акций, когда, основываясь на внутренней информации, считают цены акций завышенными. Следовательно, при объявлении о новом выпуске акций рациональный инвестор понизит оценку их текущей стоимости. По этой причине цена акций корректно оцененных «хороших» компаний, осуществляющих эмиссию с целью привлечения средств для финансирования инвестиционных проектов с положительной приведенной стоимостью, во время объявления 
о дополнительном выпуске упадет, так как нет четких критериев для разграничения «хороших» и «плохих» компаний, размещающих акции.

\section{Факторы, влияющие на реакцию рынка на объявление о дополнительной эмиссии акций}

Предшествуюшая избыточная доходность и объем эмиссии

Рассматривая факторы, которые влияют на величину эффекта объявления, Аскуис и Маллинз обнаружили, что избыточная доходность в день объявления имеет обратную зависимость от размера эмиссии, выраженной в процентах от стоимости акционерного капитала компании, и прямую зависимость от накопленной избыточной доходности (cumulative excess return, CER) за предшествующий год до объявления о дополнительной эмиссии. Таким образом, большее снижение цены акций испытывают компании с большим объемом эмиссии и низкой доходностью до размещения. Авторы ссылаются на выводы модели Майерса - Мажлуфа, согласно которым компании стремятся выпускать акции после того, как цены на них вырастут, чтобы минимизировать неблагоприятное воздействие факторов, влияющих на цены акций.

\section{Характер корпоративных новостей}

Исследование Роберта Коражчика, Дебора Лукаса и Роберта Макдоналда (Korajczyk, Lucas, McDonald, 1991) показало, что отрицательный эффект объявления о SEO существенно ниже после поступления хороших новостей, представленных в годовых и квартальных отчетах корпораций (это также соответствует модели неблагоприятного отбора). Следовательно, компании, обладающие внутренней информацией о том, что истинная стоимость их акций выше рыночной, предпочтут дождаться публикации корпоративной отчетности. Компании же с плохими внутренними новостями станут, напротив, осуществлять эмиссию акций до того момента, когда такие новости будут обнародованы.

\section{Совокупный объем эмиссии акичии и стадия экономического ичикла}

Марк Бэйлесс и Сюзан Чаплински (Bayless, Chaplinsky, 1996), анализируя данные в разбивке по периодам, в которые наблюдались высокие и низкие объемы размещений, обнаружили, что реакция цены акций на объявление о SEO в «горячие» периоды в среднем на два процентных пункта меньше по сравнению с реакцией в периоды низких объемов размещений акций. Меньший отрицательный эффект объявления в периоды больших объемов авторы объяснили меньшей информационной асимметрией между менеджерами и инвесторами. На наш взгляд, объяснение лежит несколько в иной плоскости. Разницу в размере информационной асимметрии на «горячем» и депрессивном рынке доказать трудно. Меньшая негативная реакция может являться свидетельством оптимистичного настроя инвесторов, которые, как хорошо известно, более лояльны к эмитентам (например, закрывают глаза на плохие новости) в периоды бума.

Альтернативное объяснение зависимости эффекта объявления от стадии экономического цикла в своем исследовании предложили Хьюк Чо, Роналд Масулис и Викрам Нанда (Choe, Masulis, Nanda, 1993). По их мнению, отрицательная реакция рынка на объявления о размещении акций компании слабее, когда экономика находится в фазе высокой деловой активности, т.е. в периоды с благоприятными экономическими перспективами на ближайшее будущее. В такие периоды, объявления о выпуске акций предположительно несут в себе меньше неблагоприятной информации, сказывающейся на цене акций.

\section{Целевое использование привлеченных средств}

Согласно исследованию Куил Джунг, Йонг-Чиол Ким и Рене Штульц (Jung, Kim, Stulz, 1996), реакция рынка положительно связана с инвестиционными возможностями компании, которые определяются по коэффициенту отношения рыночной стоимости акций к ее 
балансовой стоимости (market-to-book, $M / B$ ). Цена акций компаний, не имеющих хороших инвестиционных возможностей, демонстрирует более сильную отрицательную реакцию на объявление о SEO, чем компаний, такими возможностями обладающих. Кроме того, компании, планирующие рефинансировать долгосрочные займы, получают значительно меньшую избыточную доходность в период объявления, чем компании, которые собираются использовать привлеченные средства для погашения краткосрочных займов или инвестиций в оборотный капитал. Авторы отмечают, что если компаниям удается убедить рынок в том, что привлеченный капитал будет направлен на финансирование действительно стоящих проектов, снижение цены акций компании-эмитента будет существенно меньше.

Марк Уолкер и Кевен Йост (Walker, Yost, 2008) также подтвердили, что рынок положительно интерпретирует объявление о проведении SEO, если у компании есть хорошие инвестиционные возможности. Они выявили, что компании, которые намерены инвестировать привлеченные средства сразу, в среднем получают отрицательную доходность на один процентный пункт меньше, чем те, которые собираются направить привлеченные средства на погашение обязательств, финансирование оборотного капитала или общие корпоративные цели.

\section{Недооценка акций при дополнительном размещении}

Феномен недооценки, присущий первичным размещениям акций, наблюдается и в отношении дополнительных размещений. Недооценка измеряется в процентах по следующей формуле: разница между ценой закрытия в первый день после размещения и ценой размещения акций, деленная на цену размещения, то есть так же, как и при IPO. Разница между ценой закрытия в последний день перед размещением и ценой размещения, деленная на цену закрытия в последний день перед размещением, называется скидкой при размещении. Несмотря на отличие понятий, недооценка и скидка при SEO зачастую используются как взаимозаменяемые термины.

Первым феномен недооценки задокументировал Клифорд Смит (Smith, 1977), который обнаружил, что в 1971-1975 годах для рынка США цена предложения SEO была в среднем на $0,57 \%$ ниже цены закрытия предыдущего дня, а средняя доходность акций, рассчитанная как разница между ценой предложения и ценой закрытия в день размещения, составляла 0,82\%. Изучив 1608 SEO, проведенных в 1980-1984 годах, Клаудио Лодерер, Денис Шихан, Грегори Кадлеч (Loderer, Sheehan, Kadlec, 1991) выявили среднюю недооценку акций в размере $1,4 \%$.

Результаты основных исследований, посвященных недооценке SEO, обобщены в таблице 2. Как видно, величина недооценки в США с течением времени росла. Так, в период с 1971 по 1975 год была задокументирована недооценка в размере 0,5\% (Smith, 1977), в течение 1980-1984 годов - 1,4\% (Loderer, Sheehan, Kadlec, 1991), в 1986-1999 годах - 3\% (Mola, Loughran, 2004).

Таблица 2

Результаты основных эмпирических исследований размера недооценки при дополнительном размещении акций

\begin{tabular}{lccccc}
\hline \multicolumn{1}{c}{ Исследование } & $\begin{array}{c}\text { Отрасль } \\
\text { эмитента }\end{array}$ & $\begin{array}{c}\text { Размер } \\
\text { выборки }\end{array}$ & $\begin{array}{c}\text { Период } \\
\text { выборки, } \\
\text { гг. }\end{array}$ & Рынок & $\begin{array}{c}\text { Скидка } \\
\text { (недооенка), } \\
\text { \% }\end{array}$ \\
\hline $\begin{array}{l}\text { Smith (1977) } \\
\text { Loderer, Sheehan, }\end{array}$ & Bce & 328 & $1971-1975$ & США & 0,54 \\
$\begin{array}{l}\text { Kadlec (1991) } \\
\text { Eckbo, Masulis (1992) }\end{array}$ & $\begin{array}{c}\text { Промыш- } \\
\text { ленность } \\
\text { Eckbo, Masulis (1992) }\end{array}$ & 1608 & $1980-1984$ & США & 1,41 \\
Комму- & 656 & $1963-1981$ & США & 0,44 \\
& & $1963-1981$ & США & 0,31
\end{tabular}


нальное

хозяйство

Safieddine, Wilhelm

(1996)

\begin{tabular}{|c|c|c|c|c|}
\hline Bce & 474 & 1980-1991 & США & 0,55 \\
\hline Bce & 1017 & 1983-1988 & США & 1,34 \\
\hline Bce & 2287 & 1988-1998 & США & 2,99 \\
\hline Bce & 1703 & 1990-1998 & США & 2,47 \\
\hline Bce & 4454 & 1980-1998 & США & 2,21 \\
\hline Bce & 4814 & 1986-1999 & США & 3,00 \\
\hline Bce & 1040 & 1989-2000 & США & 3,45 \\
\hline Bce & 17152 & 1991-2004 & $\begin{array}{c}\text { Глобаль- } \\
\text { ный }\end{array}$ & 4,48 \\
\hline Bce & 3160 & 1991-2004 & Европа & 7,32 \\
\hline Bce & 200 & 1984-1994 & $\begin{array}{l}\text { Велико- } \\
\text { британия }\end{array}$ & 17,00 \\
\hline Bce & 306 & 1989-1997 & Гонконг & 5,78 \\
\hline Bce & 2406 & 2002-2008 & $\begin{array}{c}\text { Австра- } \\
\text { лия }\end{array}$ & 12,12 \\
\hline
\end{tabular}

Предложено несколько гипотез, объясняющих существование и динамику недооценки при дополнительном размещении акций. Среди них: изменения профиля эмитента, коротких продаж, «приятного послевкусия», растущей власти инвестиционных банков.

\section{Гипотеза изменения профиля эмитента}

Гипотеза изменения профиля эмитента подразумевает, что компании, выпустившие дополнительные акции относительно недавно (т.е. в последние 15 лет), имеют более высокий уровень риска (связанный с высоким уровнем неопределенности), чем эмитенты, осуществившие размещения в более ранние периоды. Растущее количество рискованных SEO должно приводить к увеличению среднего размера скидки при SEO. Проанализировав выборку эмитентов в разбивке по таким переменным, как биржа листинга, объем эмиссии и отраслевая принадлежность эмитента, Франческа Мола и Тим Лоугран (Mola, Loughran, 2004) пришли к выводу, что изменение структуры выборки компаний частично объясняет рост недооценки. На протяжении 1990-х годов на рынок с дополнительными размещениями акций выходили в основном компании из отрасли высоких технологий и компании, котирующиеся на бирже NASDAQ. Как правило, размещения на NASDAQ и размещения высокотехнологичных компаний отличаются более высоким уровнем неопределенности и соответственно большей величиной недооценки. Средний размер недооценки SEO на бирже NASDAQ, где концентрировалось больше молодых компаний с меньшей капитализацией, чем на биржах AMEX и NYSE, вырос в период 1986-1999 годов с 1,0 до 4,5\% (Mola, Loughran, 2004). К такому же результату пришли и авторы работ (Kim, Shin, 2004) и (Kim, Park, 2005).

\section{Гипотеза коротких продаж}

Гипотеза коротких продаж подразумевает, что трейдеры, играющие на понижение (short-sellers), вынуждают андеррайтеров размещать дополнительные акции по ценам ниже цен закрытия предыдущих дней. Согласно данной гипотезе, предложенной Майклом Барклаем и Робертом Литзенбергером (Barclay, Litzenberger, 1988), применительно к скидке к дополнительным размещениям акций спекулянты намеренно сбивают рыночную цену, чтобы таким образом повлиять на цену размещения новых акций и затем зафиксировать прибыль, купив акции по сниженной цене. Следовательно, короткие продажи могут 
уменьшать степень информативности цен вторичного рынка перед размещением. В результате компания-эмитент вынуждена предлагать скидку большего размера, чтобы продать новые акции. Данная гипотеза базируется на предположении о том, что андеррайтер, как правило, опирается на предыдущую цену закрытия при установлении цены размещения.

\section{Гипотеза «приятного послевкусия»}

Гипотеза приятного послевкусия (leaving a good taste hypothesis) была предложена Роджером Ибботсоном (Ibbotson, 1975). Данная гипотеза описывает мотивы, по которым эмитенты идут на недооценку при размещении первичных и дополнительных акций. Во время первичных размещений эмитенты предпочитают «оставить на столе» для инвесторов некоторую сумму денег (т.е. разместить акции с недооценкой), поскольку планируют в будущем вернуться на рынок с целью дополнительного привлечения средств. Допущение данной гипотезы состоит в том, что инвестор помнит, какой была для него сделка при первичном размещении - хорошая или плохая. Если по прошествии времени инвесторы сочли сделку неудачной для себя, то в этом случае от эмитента и андеррайтера потребуются большие маркетинговые усилия при проведении SEO и большая скидка с текущей цены для успешного размещения выпуска. Исследование Мола и Лоуграна (Mola, Loughran, 2004) выявило, что средняя величина скидки SEO компаний, не проводивших и проводивших размещение акций в предшествующем году, равна 3,9 и 2,2\% соответственно. Этот результат вполне вписывается в гипотезу «приятного послевкусия», согласно которой инвесторы запрашивают скидку тем меньшего размера, чем чаще компания проводит эмиссию.

\section{Гипотеза растущей власти инвестиционных банков}

Мола и Лоугран (Mola, Loughran, 2004) исследовали важность аналитического покрытия компаний, осуществивших SEO, и факторы, которые определяют рыночную долю андеррайтера. Авторы отмечают увеличивающуюся значимость аналитического покрытия андеррайтерами как источника власти инвестиционных банков и расширение практики установления цен размещения банками-андеррайтерами в целых числах. Если цены размещения SEO установлены в целых числах, то скидка больше: она составляет 3,9\%, в то время как при цене размещения, выраженной в дробных числах, - 2,4\%. Рост скидки в период с 1986 по 1999 год говорит о том, что эмитенты не пытаются минимизировать размер недооценки SEO. Вместо этого, менеджмент компаний-эмитентов фокусируется на выборе андеррайтера, который будет агрессивно продавать их акции. Хотя в исследовавшийся период при проведении SEO больше средств «оставалось на столе», чем до 1986 года, компании шли на значительную недооценку, так как, по их мнению, распространение положительных отчетов об их деятельности, подготовленных более влиятельной аналитической группой, способствует росту цены акций. Это привело авторов к выводу, что инвестиционные банки с влиятельной аналитической группой могут устанавливать цены таким образом, чтобы «оставить на столе» больше денег для своих привилегированных клиентов.

Однако результаты исследования Ойа Алтинкилича и Роберта Хансена (Altinkilic, Hansen, 2003) 1703 SEO, проведенных в США в период 1980-1997 годов, не подтверждают гипотезу растущей власти инвестиционных банков. Напротив, как было выявлено, у эмитентов с высоко котирующимися акциями, к тому же имеющих более авторитетный ведущий банк в андеррайтинговом синдикате, скидка при SEO меньше, чем у компаний, организатором размещения которых выступал банк с более скромной репутацией. По мнению авторов работы, инвестиционные банки стремятся устанавливать справедливую цену и не закладывают недооценку в ценовой диапазон с целью извлечения выгод.

\section{Долгосрочная доходность SEO}

Первым обратил внимание на пониженную долгосрочную доходность дополнительных 
размещений Пол Марш (Marsh, 1979), исследовавший SEO в Великобритании, но наибольший интерес к этой проблеме был вызван публикацией исследований Тима Лоуграна и Джей Риттера (Loughran, Ritter, 1995), а также Катрин Спис и Джона Аффлек-Грэйвса (Spiece, Affleck-Graves, 1995). Лоугран и Риттер, используя выборку из 3702 SEO, проведенных в 1970-1990 годах, выяснили, что акции компаний, выпустивших дополнительные акции, имели значительно более низкую доходность по сравнению с доходностью бумаг сопоставимых компаний (схожих по размеру, без учета отраслевой принадлежности), не выпускавших акции в последние пять лет. Средняя ежегодная доходность акций при SEO в течение пяти лет после эмиссии составляла 7\% по сравнению с 15\%-ной доходностью аналогичных компаний, не размещавших дополнительные акции. Средняя доходность инвестирования (buy-and-hold return) в акции компаний, осуществивших SEO, на интервале в пять лет составляла $33,4 \%$, в то время как для компаний-аналогов этот показатель достигал 92,8\%. Спис и Аффлек-Грэйвс также зафиксировали, что компании, осуществивщие SEO в 1975-1989 годах, имели значительно более низкую доходность по сравнению с аналогичными (в отраслевом разрезе и по размеру) компаниями, не размещавшими акции. Пониженная доходность имела место даже после учета биржи листинга, объема размещения, возраста эмитента и коэффициента отношения балансовой стоимости акций к ее рыночной стоимости (book-to-market ratio, $B / M$ ).

Сводная информация по основным исследованиям долгосрочной доходности представлена в таблице 3. Из таблицы видно, что долгосрочная доходность акций при SEO отрицательна, если период владения акциями длится от 3 до 5 лет.

Таблица 3

Результаты основных исследований долгосрочной доходности акций SEO

\begin{tabular}{|c|c|c|c|c|c|c|}
\hline Исследование & $\begin{array}{c}\text { Отрасль } \\
\text { эмитента }\end{array}$ & $\begin{array}{c}\text { Размер } \\
\text { выборки }\end{array}$ & $\begin{array}{c}\text { Период } \\
\text { выборки, } \\
\text { гг. }\end{array}$ & Рынок & $\begin{array}{c}\text { Период } \\
\text { владе- } \\
\text { ния, } \\
\text { месяцев }\end{array}$ & $\begin{array}{c}\text { Избыточная } \\
\text { доходность } \\
\left(\text { BHAR }^{*}\right), \%\end{array}$ \\
\hline $\begin{array}{l}\text { Loughran, Ritter } \\
\text { (1995) }\end{array}$ & Bce & 3702 & 1970-1990 & США & 36 & $-33,00$ \\
\hline $\begin{array}{l}\text { Loughran, Ritter } \\
\text { (1995) }\end{array}$ & Bce & 3702 & 1970-1990 & США & 60 & $-59,40$ \\
\hline $\begin{array}{l}\text { Spiess, Affleck- } \\
\text { Graves (1995) }\end{array}$ & Bce & 1247 & 1975-1989 & США & 36 & $-22,80$ \\
\hline Lee (1997) & Bce & 1513 & 1976-1990 & США & 36 & $-20,30$ \\
\hline Jegadeesh (2000) & Bce & 2992 & 1970-1993 & США & 60 & $-34,30$ \\
\hline $\begin{array}{l}\text { Brav, Geczy, } \\
\text { Gompers (2000) }\end{array}$ & Bce & 3775 & 1975-1992 & США & 60 & $-26,30$ \\
\hline $\begin{array}{l}\text { Eckbo, Masulis, } \\
\text { Norli (2000) }\end{array}$ & $\begin{array}{c}\text { Промышле } \\
\text { нность }\end{array}$ & 3851 & 1964-1995 & США & 60 & $-23,20$ \\
\hline Kahle (2000) & $\begin{array}{c}\text { Промышле } \\
\text { нность }\end{array}$ & 1739 & 1981-1992 & США & 36 & $-14,70$ \\
\hline $\begin{array}{l}\text { Eckbo, Masulis, } \\
\text { Norli (2007) }\end{array}$ & $\begin{array}{c}\text { Промышле } \\
\text { нность }\end{array}$ & 4971 & 1980-2000 & США & 60 & $-29,70$ \\
\hline $\begin{array}{l}\text { Eckbo, Masulis, } \\
\text { Norli (2007) }\end{array}$ & $\begin{array}{c}\text { Финансовая } \\
\text { отрасль }\end{array}$ & 655 & $1980-2000$ & США & 60 & 0,00 \\
\hline $\begin{array}{l}\text { Eckbo, Masulis, } \\
\text { Norli (2007) }\end{array}$ & $\begin{array}{c}\text { Коммуналь } \\
\text { ное } \\
\text { хозяйство }\end{array}$ & 659 & $1980-2000$ & США & 60 & $-19,10$ \\
\hline Ho (2005) & Bce & 627 & 1989-1997 & $\begin{array}{c}\text { Великобр } \\
\text { итания }\end{array}$ & 36 & $-19,50$ \\
\hline Andrikopoulos & Bce & 1542 & 1988-1998 & Великобр & 36 & $-26,20$ \\
\hline
\end{tabular}


(2009)

Cai, Loughran

(1998)

Eckbo, Norli

(2004)

Mathew (2002)

Mathew (2002)

Mathew (2002)

* BHAR - Buy-and-Hold Abnormal Return.

\begin{tabular}{llllll} 
Bce & 1389 & $1971-1992$ & Япония & 60 & $-29,10$ \\
Bce & 221 & $1980-1993$ & Норвегия & 36 & $-22,60$ \\
Bce & 744 & $1977-1992$ & Япония & 36 & $-36,69$ \\
Bce & 415 & $1977-1992$ & Корея & 36 & $-17,38$ \\
Bce & 313 & $1982-1992$ & Гонконг & 36 & $-36,77$ \\
\hline
\end{tabular}

итания

Пониженную долгосрочную доходность, выявленную многими авторами, связывают с использованием модели, некорректно специфицированной самими исследователями. Альтернативное объяснение состоит в использовании окон возможностей эмитентами.

\section{Проявление некорректно специифицированной модели}

Эспен Екбо, Роналд Масулис и Ойвинд Норли (Eckbo, Masulis, Norli, 2000) считают, что методика сопоставления компаний, предложенная Лоуграном и Риттером, искусственно «производит» избыточную доходность. Исследовав более 7000 дополнительных размещений акций и облигаций за период 1964-1995 годов, авторы пришли к выводу, что пониженная доходность SEO объясняется тем, что: а) у компаний, проводивших дополнительные размещения, ниже доля долга в структуре капитала, а следовательно, и риск банкротства и т.П., б) SEO повышают ликвидность акций. Соответственно акции компаний, проводившие $\mathrm{SEO}$, являются менее рисковыми, и требуемая доходность инвесторов при вложении в данные акции, ниже, чем для публичных компаний в целом (Eckbo, Masulis, Norli, 2000).

Марей Карлсон и его соавторы (Carlson, Fischer, Giammarino, 2006) смотрят на пониженную доходность SEO сквозь призму реальных опционов. В их теоретической модели дополнительное размещение акций всегда связано с ростом компании. По мере того как компании растут, они привлекают все больше средств для конвертирования реальных опционов в существующие активы, а приобретаемые активы менее рискованны, чем реальные опционы. Уменьшение риска по сравнению с компаниями-аналогами, не выпускающими акции, и объясняет долгосрочную пониженную доходность в духе Лоуграна и Риттера. Интерпретация пониженной доходности Карлсона и его соавторов с помощью модели реальных опционов близка к аргументам Екбо, согласно которым выпуск акций снижает риск дефолта компании. То есть общим фактором, объясняющим пониженную долгосрочную доходность, в обоих случаях является уменьшение риска за счет прироста инвестиций в основные средства.

Юджин Фама (Fama, 1998) также считает спорным вывод Лоуграна и Риттера (Loughran, Ritter, 1995) о том, что дополнительные размещения акций передают рынку новую информацию о значительной переоценке эмитента, которую в свою очередь рынок игнорирует. Фама утверждает, что поскольку будущая доходность акций зависит от таких факторов, как размер компании, отношение балансовой стоимости ее акций к рыночной и прошлая доходность, а в исследовании Лоуграна и Риттера контролируется только размер компании, найденный ими эффект отрицательной избыточной долгосрочной доходности нельзя считать аномалией. На взгляд авторов данной статьи, логика Фамы может быть подвергнута сомнению: отношение балансовой стоимости акций к рыночной и их прошлая доходность необязательно должны считаться экзогенными факторами и не должны контролироваться в исследованиях подобного рода. Отношение балансовой стоимости к рыночной может не только являться оценкой рынком наличия у компании инвестиционных проектов, как предполагается в (Jung, Kim, Stulz, 1996), но и быть, наравне с прошлой положительной избыточной доходностью, дополнительным косвенным свидетельством того, что SEO осуществляются в периоды, когда акции переоценены.

Нарасимах Джагадиш Jegadeesh, 2000) сопоставляет доходность вложений в SEO с 
различными бенчмарками: индексы, взвешенные по стоимости, индексы с равными весами, бенчмарк, отражающий специфические характеристики компаний (коэффициент $E / P$, «прибыль/цена», запаздывающие индикаторы прибыли за шесть предыдущих месяцев и три предыдущих года), бенчмарк факторной модели. Результаты анализа 2992 SEO, проведенных на биржах AMEX, NASDAQ, NYSE с 1970 по 1993 год, даже после сравнения с наиболее подходящими бенчмарками свидетельствуют о робастности пониженной доходности. Пониженная доходность акций компаний, проводивших SEO относительно бенчмарка сопоставимых по размеру компаний, составляет 47,5\%. Пониженная доходность акций SEO относительно бенчмарка сопоставимых по размеру и коэффициенту $M / B$ (отношение рыночной стоимости акций к балансовой) компаний равна $34,3 \%$. Джагадиш приходит к выводу, что пониженная доходность обусловлена чрезмерным оптимизмом и завышенными ожиданиями будущих прибылей компаний эмитентов.

\section{Использование окон возможностей}

Лоугран и Риттер (Loughran, Ritter, 1995) считают основной причиной пониженной долгосрочной доходности акций IPO и SEO использование окон возможностей: компании выпускают акции в тот момент, когда они переоценены. Эмпирические исследования показали, что эмитенты, осуществляющие SEO, за год до размещения демонстрируют рост операционной доходности. В свою очередь рынок переоценивает краткосрочное повышение операционной доходности и не полностью учитывает временный характер повышенной доходности. Другими словами, рынок систематически неверно оценивает автокорреляцию роста доходов. Следовательно, во время эмиссии рыночные цены отражают капитализацию временных операционных улучшений. Доходность акций понижается, как только обнаруживается непродолжительность роста операционной доходности, хотя это происходит не сразу после эмиссии.

Роберт Хансен, Клэр Кратчлей (Hansen, Crutchley, 1990) исследовали операционную доходность компаний, осуществляющих SEO. Они выявили снижение коэффициента рентабельности активов (return on assets, $R O A$ ) после эмиссии у компаний, предпринявших SEO. Роберт Маклохлин, Ассем Сафиддин, Гопала Васудеван (McLaughlin, Safieddine, Vasudevan, 1996) проанализировали изменение операционной доходности после SEO на выборке из 1296 размещений за 1980-1991 годы. В качестве показателя операционной доходности они использовали отношение свободного денежного потока от операционной деятельности к балансовой стоимости активов. В ходе исследования было установлено, что компании, проводившие SEO, имели значительный рост показателей операционной доходности до размещения, однако после него операционная доходность резко уменьшалась. Так, медиана изменения отношения свободного денежного потока к балансовой стоимости активов в среднем снижалась на $20 \%$ в течение последующих трех лет. Максимальное падение прибыльности испытывали компании с большим коэффициентом свободного денежного потока, и, напротив, минимальное падение прибыльности было характерно для компаний, инвестирующих в основные средства.

В другой работе Лоугран и Риттер (Loughran, Ritter, 1997) подтвердили факт снижения операционной доходности компаний после проведения дополнительной эмиссии акций. Используя выборку из 1338 SEO, осуществленных с 1979 по 1989 год, авторы исследования выявили снижение значения медианы рентабельности продаж с 5,4\% в отчетный год размещения до $2,5 \%$ через четыре года после размещения. Медиана $R O A$ за этот же период уменьшилась с 6,3 до 3,2\%, а медиана коэффициента отношения операционной прибыли к балансовой стоимости активов - с 15,8 до $12,1 \%$, что существенно превысило соответствующее падение у компаний, аналогичных по размеру, отраслевой принадлежности и коэффициенту операционной доходности, но не выпускающих дополнительные акции.

Авторы видят объяснение того факта, что компании, размещающие акции, показывают более низкую операционную доходность после эмиссии, в том, что менеджмент компании и инвесторы чрезмерно оптимистичны по поводу будущей прибыли эмитентов. Инвесторы 
вкладываются в проекты, которые рынок воспринимает как проекты с положительной чистой приведенной стоимостью (net present value, $N P V$ ), хотя в действительности зачастую $N P V$ проектов является отрицательной. Тем не менее эмитенты продолжают инвестировать в проекты еще активнее, даже когда снижается их доходность.

Ашик Али (Ali, 1997) также считает, что аналитики проявляют слишком большой оптимизм в своих прогнозах уровня прибыли компаний-эмитентов после SEO по сравнению с компаниями, не выпускающими дополнительных акций. Давид Денис и Атулия Сарин (Denis, Sarin 2001) подтверждают чрезмерную оптимистичность инвесторов. Исследовав реакцию рынка на публикацию отчетов о прибыли, авторы приходят к заключению, что инвесторы оказываются разочарованы низкой прибылью компаний, предпринявших дополнительную эмиссию, объясняя это тем, что рынок отрицательно реагирует на квартальные отчеты о прибыли в течение последующих трех лет начиная со 2-го квартала после SEO.

Панагиотис Андрикополус (Andrikopoulus, 2009) изучил феномен пониженной доходности SEO, осуществленных в виде эмиссии прав в Великобритании. Используя различные бенчмарки, он обнаружил, что пониженная доходность дополнительных размещений тесно связана с ухудшением показателей операционной деятельности компании (рентабельности, ROA, рентабельности чистой прибыли (net profit margin), прибыли до уплаты налогов): резкое падение доходности наблюдается сразу же после проведения SEO, и снижение показателей продолжается еще три года.

Вывод, к которому пришли Лоугран и Риттер (Loughran, Ritter, 1995), поставил под вопрос наличие рационального ценообразования на фондовых рынках. Тем не менее ряд ученых подвергли сомнению феномен пониженной доходности акций компаний, вышедших на IPO и SEO, в качестве аргументов ссылаясь на некорректное сопоставление с бенчмарком и неточный учет риска.

\section{Заключение}

Приведенный в нашей статье обзор исследований, посвященных дополнительным размещениям акций, показывает, что повторному выходу эмитентов на фондовый рынок с целью привлечения акционерного капитала свойственны следующие аномалии: эффект объявления о SEO, недооценка акций при размещении, пониженная долгосрочная доходность, снижающаяся операционная доходность компаний после SEO.

Отрицательный эффект объявления о SEO устойчив в США, однако на развитых рынках Европы и Азии новость о дополнительном размещении акций вызывает положительный или очень небольшой отрицательный эффект, что связано с различными методами размещения акций.

Аналогично IPO, при дополнительном размещении цены акции устанавливаются с дисконтом, хотя и с существенно меньшим, чем при первичном размещении. Как и в случае IPO, размер недооценки вырос за последние десятилетия, причем на рынках Европы этот показатель существенно выше, чем в США.

Наконец, наиболее дискуссионным является феномен пониженной долгосрочной доходности. Результаты рассмотренных нами исследований свидетельствуют, что об устойчивости отрицательной избыточной долгосрочной доходности на рынках США, Европы и Юго-Восточной Азии, а также о снижении после проведения SEO операционной доходности.

\section{Список использованной литературы}

1. Ali, A. (1997), Bias in Analysts' Earnings Forecasts as an Explanation for the Long-Run Underperformance of Stocks Following Equity Offerings. Working paper. University of Arizona. URL: http://ssrn.com/abstract=2796. 
2. Altinkilic, O., Hansen, R. (2003), Discounting and Underpricing in Seasoned Equity Offers, Journal of Financial Economics, 69 (2003) 285-323.

3. Andrikopoulos, P. (2009), Seasoned Equity Offerings, Operating Performance and Overconfidence: Evidence from the UK, Journal of Economics and Business, 61 (2009) 189-215.

4. Asem, E., Chung, J., Tian, G. (2009), Liquidity, Investor Sentiment and Price Discount of SEOs in Australia. Working uaper. http://www.edwards.usask.ca/centres/csfm/_files/presentations/gloria\%20tian.pdf.

5. Asquith, P., Mullins, D.W. (1986), Equity Issues and Offering Dilution, Journal of Financial Economics, 15 (1986) 61-89.

6. Barclay, M, Litzenberger, R. (1988), Announcement Effects of New Equity Issues and the Use of Intraday Data, Journal of Financial Economics, 21 (1988) 71-99.

7. Bayless, M., Chaplinsky, S.(1996), Is There a Window of Opportunity for Seasoned Equity Issuance? The Journal of Finance, 1(51) (1996) 253-278.

8. Bortolotti, B., Megginson, W., Smart, S. (2007), The Rise of Accelerated Seasoned Equity Underwritings, Working Paper University of Oklahoma. URL: http://ageconsearch.umn.edu/bitstream/12190/1/wp070005.pdf.

9. Brav, A., Geczy, C. (2000), Gompers P.A. Is the Abnormal Return Following Equity Issuances Anomalous? Journal of Financial Economics, 56 (2000) 209-249.

10. Cai, J., Loughran, T. (1998), The Performance of Japanese Seasoned Equity Offerings. 1971-1992, Pacific-Basin Finance Journal, 6 (1998) 395-425.

11. Carlson, M., Fisher, A., Giammarino, R. (2006), Corporate Investment and Asset Price Dynamics: Implication for SEO Event Studies and Long-Run Performance, The Journal of Finance, 61 (2006) 1009-1034.

12. Choe, H., Masulis, R., Nanda, V. (1993), Common Stock Offerings Across The Business Cycle: Theory and Evidence, Journal of Empirical Finance, 1 (1993) 3-31.

13. Corwin, S. (2003), The Determinants of Underpricing for Seasoned Equity Offers, Journal of Finance, 58 (2003) 2249-2279.

14. Cronqvist, H., Nilsson, M. (2005), The Choice Between Rights Offerings and Private Equity Placements, Journal of Financial Economics, 78 (2005) 375- 407.

15. Denis, D., Sarin, A. (2001), Is the Market Surprised by Poor Earnings Realizations Following Seasoned Equity Offerings? The Journal of Financial and Quantitative Analysis, 36 (2001) 169-193.

16. D’Mello, R., Schlingemann, F., Subramaniam, V. (2009), Are There Monitoring Benefits To Institutional Ownership? Evidence from Seasoned Equity Offerings. Working paper, Tulane University. URL: http://ssrn.com/abstract $=1653857$

17. Eckbo, B., Masulis, R. Adverse Selection and the Rights Offer Paradox, Journal of Financial Economics, 32 (1992) 293-332.

18. Eckbo, B., Masulis, R., Norli, O. (2007), Security offerings. In: Eckbo, B. (ed.), Handbook of Corporate Finance: Empirical Corporate Finance // Handbooks in Finance Series. Elsevier/North Holland Co., Amsterdam.

19. Eckbo, B., Norli, O. (2004), The Choice of Seasoned-Equity Selling Mechanism: Theory and Evidence. Working paper Tuck School of Business at Dartmouth. URL: http://ssrn.com/abstract $=709143$.

20. Eckbo, E.,Masulis, R.,Norli, O. (2000), Seasoned Public Offerings: Resolution of the 'New Issue Puzzle'. Journal of Financial Economics, 56 (2000) 251-291.

21. Fama, E. Market Efficiency, Long-term Returns, and Behavioral Finance. Journal of Financial Economics, 49 (1998) 283-306.

22. Gajewski, J., Ginglinger, E. (2002), Seasoned Equity Issues in a Closely Held Market: Evidence from France. European Finance Review, 6(3) (2002) 291-319.

23. Hansen, R., Crutchley, C. (1990), Corporate Earnings and Financings: An Empirical Analysis, The Journal of Business, 63 (1990) 347-371. 
24. Ho, K. (2005), Long-Horizon Abnormal Performance Following Rights Issues and Placings: Additional Evidence from the U.K. Market. Review of Financial Economics, 14 (2005) 2545.

25. Ibbotson, R. (1975), Price Performance of Common Stock New Issues. Journal of financial economics, 2 (1975) 235-272.

26. Jegadeesh, N. (2000), Long-Term Performance of Seasoned Equity Offerings: Benchmark Errors and Biases in Expectations. Financial Management, 29 (2000) 5-30.

27. Jung, K., Kim, Y., Stulz R. (1996), Managerial Discretion, Investment Opportunities, and the Security Issue Decision, Journal of Financial Economics, 42 (1996) 159-185.

28. Kahle, K.M. (2000), Insider Trading and the Long-Run Performance of New Security Issues, Journal of Corporate Finance, 6 (2000) 25-53.

29. Kang, J., Stulz, R. (1996), How Different Is Japanese Corporate Finance? An Investigation of the Information Content of New Security Issues, Review of Financial Studies, 9 (1996) 109-139.

30. Kim, K., Shin, H. (2001), The Underpricing of Seasoned Equity Offerings: 1983-1998. Working Paper. URL: http://ssrn.com/abstract=275845.

31. Kim, Y., Park, M. (2005), Pricing of Seasoned Equity Offers and Earnings Management, The Journal of Financial and Quantitative Analysis, 2(140) (2005) 435-463.

32. Korajczyk, R., Lucas, D., McDonald, R. (1991), The Effect of Information Releases on the Pricing and Timing of Equity Issues, The Review of Financial Studies, 4(4) (1991) 685-708.

33. Lee, I. (1997), Do Firms Knowingly Sell Overvalued Equity? Journal of Finance, 52 (1997) 1439-1466.

34. Loderer, C., Sheehan, D., Kadlec, G. (1991), The Pricing of Equity Offerings, Journal of Financial Economics, 29 (1991) 35-57.

35. Loughran, T., Ritter, J. (1995), The New Issues Puzzle, The Journal of Finance, 50 (1995) 23-51.

36. Loughran, T., Ritter, J. (1997), The Operating Performance of Firms Conducting Seasoned Equity Offerings, The Journal of Finance, 52 (1997) 1823-1850.

37. Marsh, P. Equity Rights Issues and the Efficiency of the UK Stock Market, The Journal of Finance, 34 (1979) 839-862.

38. Masulis, R., Korwar, A. (1986), Seasoned Equity Offerings an Empirical Investigation, Journal of Financial Economics, 15 (1986) 91-118.

39. Mathew, P. (2002), Long-horizon Seasoned Equity Offerings Performance in Pacific Rim markets, Review of Financial Economics, 11 (2002) 317-333.

40. McLaughlin, R., Safieddine, A., Vasudevan, G. (1996), The Operating Performance of Seasoned Equity Issuers: Free Cash Flow and Post-Issue Performance, Financial Management, 25 (1996).

41. Mikkelson, W., Partch, M. (1986), Valuation Effects of Security Offerings and the Issuance Process, Journal of Financial Economics, 15 (1986) 30-60.

42. Mola, S., Loughran, T. (2004), Discounting and Clustering in Seasoned Equity Offerings Prices, Journal of Financial and Quantitative Analysis, 39 (2004) 1-23.

43. Myers, S., Maljuf, N. (1984), Corporate Financing and Investment Decisions When Firms Have Information That Investors Do Not Have, Journal of Financial Economics, 13 (1984) 187-222.

44. Safieddine, A.,Wilhelm, W. (1996), An Empirical Investigation of Short-selling Activity Prior to Seasoned Equity Offerings, Journal of Finance, 51 (1996) 729-749.

45. Scholes, M. (1972), The Market for Securities: Substitutions Versus rice Pressure and the Effects of information.

46. Slovin, M., Sushka, M., Lai, K. (2000), Alternative Flotation Methods, Adverse Selection, and Ownership Structure: Evidence from Seasoned Equity Issuance in the U.K., Journal of Financial Economics, 57 (2000) 157-190.

47. Smith, C.W. (1977), Alternative Methods for Raising Capital: Rights versus Underwritten 
Offerings, Journal of Financial Economics, 5 (1977) 273-307.

48. Spiess, K. (1995), Affleck-Graves J. Underperformance in Long-run Stock Returns Following Seasoned Equity Offerings, Journal of Financial Economics, 38 (1995) 243-267.

49. Walker, M., Yost, K. (2008), Seasoned Equity Offerings: What Firms Say, Do, and How the Markets Reacts, Journal of Corporate Finance, 14 (2008) 376-386.

50. Wu, X., Wang, Z., Yao, J. (2005), Understanding the Positive Announcement Effects of Private Equity Placements: New Insights from Hong Kong Data, Review of Finance, 9 (2005) 385-414. 